\title{
Correction of Crowding using Conservative Treatment Approach
}

\author{
Dr Tapan Shah,' Dr Tarulatha Shyagali,2 Dr Kalyani Trivedi ${ }^{3}$ \\ isenior Lecturer, ${ }^{2}$ Professor, Department of Orthodontics, Darshan Dental College, Udaipur, India \\ 3Professor, Department of Orthodontics, Karnavati Dental College, Ahmedabad, India \\ Correspondence: Dr Tarulatha Shyagali; email: drtarulatha@gmail.com
}

\section{INTRODUCTION}

In the plethora of orthodontic chief complaints, crowding and proclination have etched their importance by being in the top of the list. Diagnosis and treatment planning in such cases are challenging as well as demanding. Diagnosis in the form of model analysis, radiographic analysis, soft tissue analysis; all have their share of contribution in deciding the treatment plan. However, the most valid treatment option is at the discretion of the patient's choice and orthodontist can merely guide them in the direction of what is good for them.

One of the most popular non-extraction treatment modalities is the arch expansion and by utilizing the expansion space one can correct the crowding. With the advent of temperature activated wires, we are equipped with efficient appliance like NiTi palatal expander, which can produce the efficient physiological expansion.' Apart from the conventional extraction protocol, one can think of single lower incisor extraction to bring about the correction without compromising the ideal occlusion. ${ }^{2.3}$

The present article is a case report of one such case of crowding treated using the combination of extraction and non-extraction treatment modality.

\section{Case report}

An 11-year-old male patient presented with a chief compliant of forwardly placed upper front teeth. On examination, he was having a convex profile with retrognathic mandible and posterior divergence (Figure 1a-1c). The intra-oral examination
(Figure 2a-2e) revealed Angle's Class I malocclusion with $5 \mathrm{~mm}$ overjet and $7 \mathrm{~mm}$ overbite. The upper anterior teeth were moderately crowded and the lower anterior teeth were severely crowded with a lingually erupted lateral incisor on left side. Transverse asymmetry was seen in upper arch and the arch was narrow in the premolar region. Lower dental midline was shifted to left by $3 \mathrm{~mm}$. Gingival recession was seen in the lower left central incisor region. The oral hygiene status was poor. It was a typical case of arch length-arch width-tooth material discrepancy. The upper incisors were traumatized.

The radiographic examination presented with skeletal Class I (Figure 3a-3b) with average growth pattern and proclined upper and lower incisors (Table 1). Bolton's model analysis showed mandibular teeth excess in both overall and anterior ratio calculations and Pont's index showed the requirement of expansion in both premolar and molar regions.

\section{Diagnosis}

Angle's Class I dental malocclusion with increased overjet and overbite with severe lower anterior crowding based on skeletal Class I jaw bases, with average growth pattern and proclined upper incisors.

\section{Treatment objectives:}

1. To treat traumatic upper incisors

2. To relieve crowding of upper and lower arches

3. To expand constricted arches

4. To establish normal overjet and overbite relation

5. To establish proper inclination of upper incisors. 

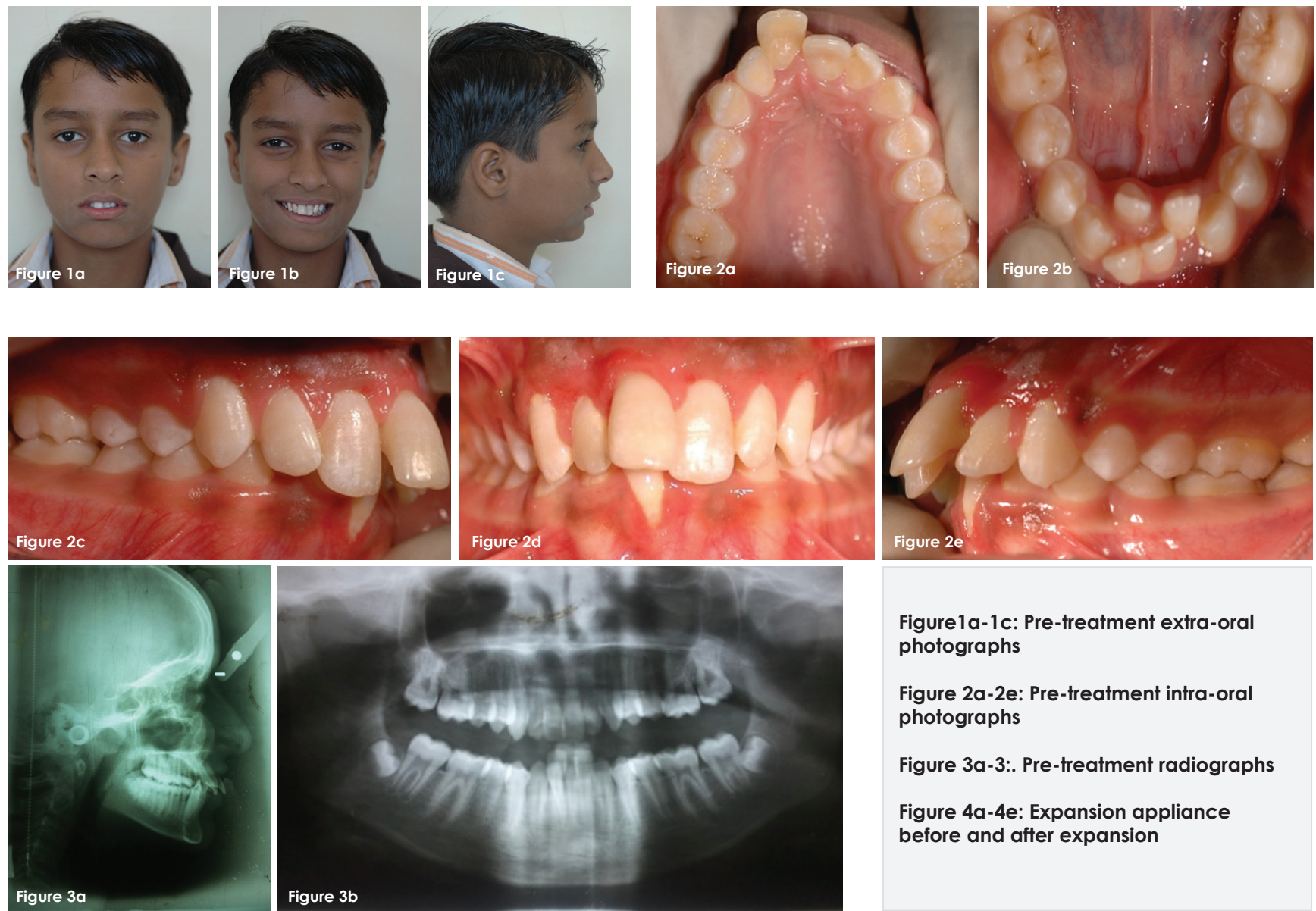

Figure1a-1c: Pre-treatment extra-oral photographs

Figure 2a-2e: Pre-treatment intra-ora photographs

Figure 3a-3:. Pre-treatment radiographs

Figure 4a-4e: Expansion appliance before and after expansion
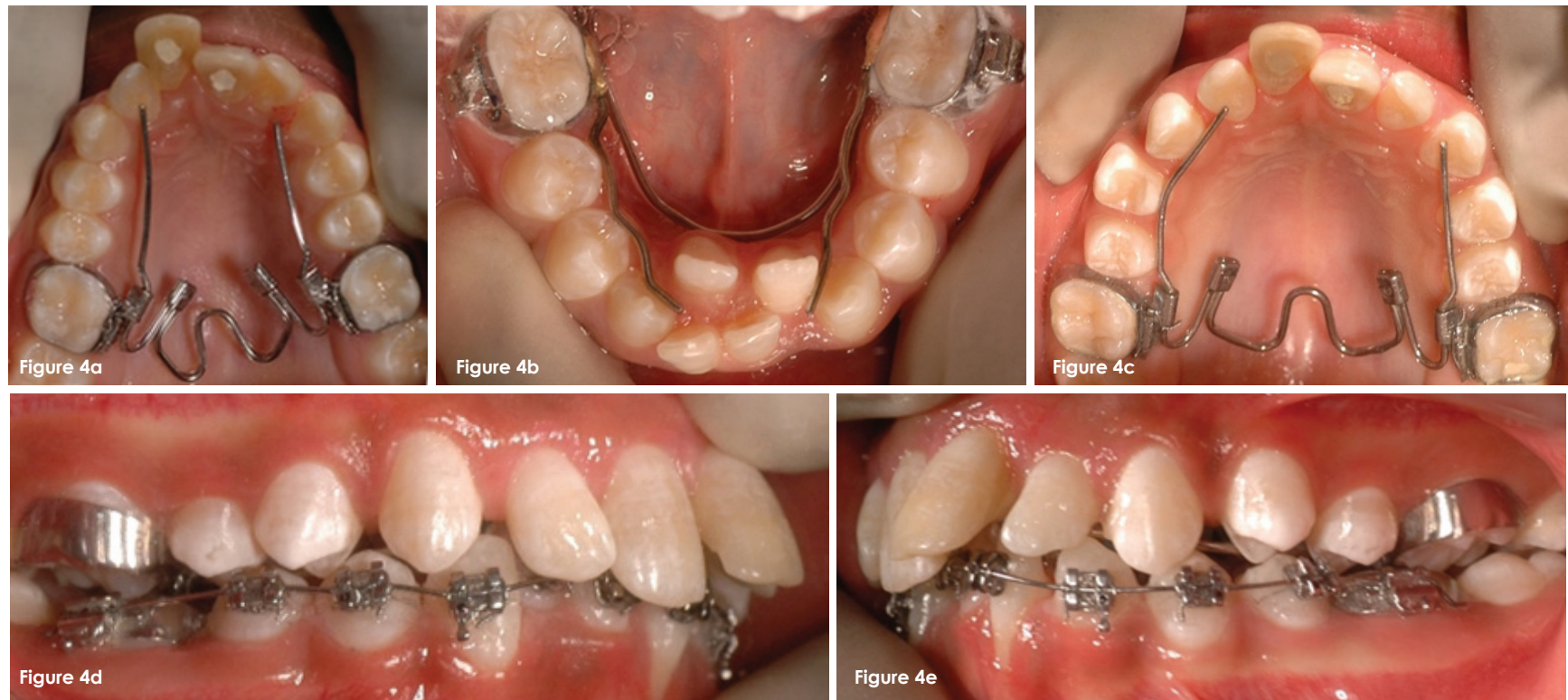

\section{Treatment plan}

After analyzing the case, the initial treatment plan was to follow the non-extraction treatment modality by expanding the upper and lower arch. Alternative treatment plan was to extract all first premolars of upper and lower jaws and treat the case using Group B anchorage.

\section{Treatment progress}

Root canal treatment was done for upper central incisors at the beginning of the treatment. Upper and lower arches were expanded using NiTi palatal expander and bi-helix respectively (Figure $4 a-4 b$ ). Once the desired amount of expansion was achieved (Figure 4c-4e), upper and lower 

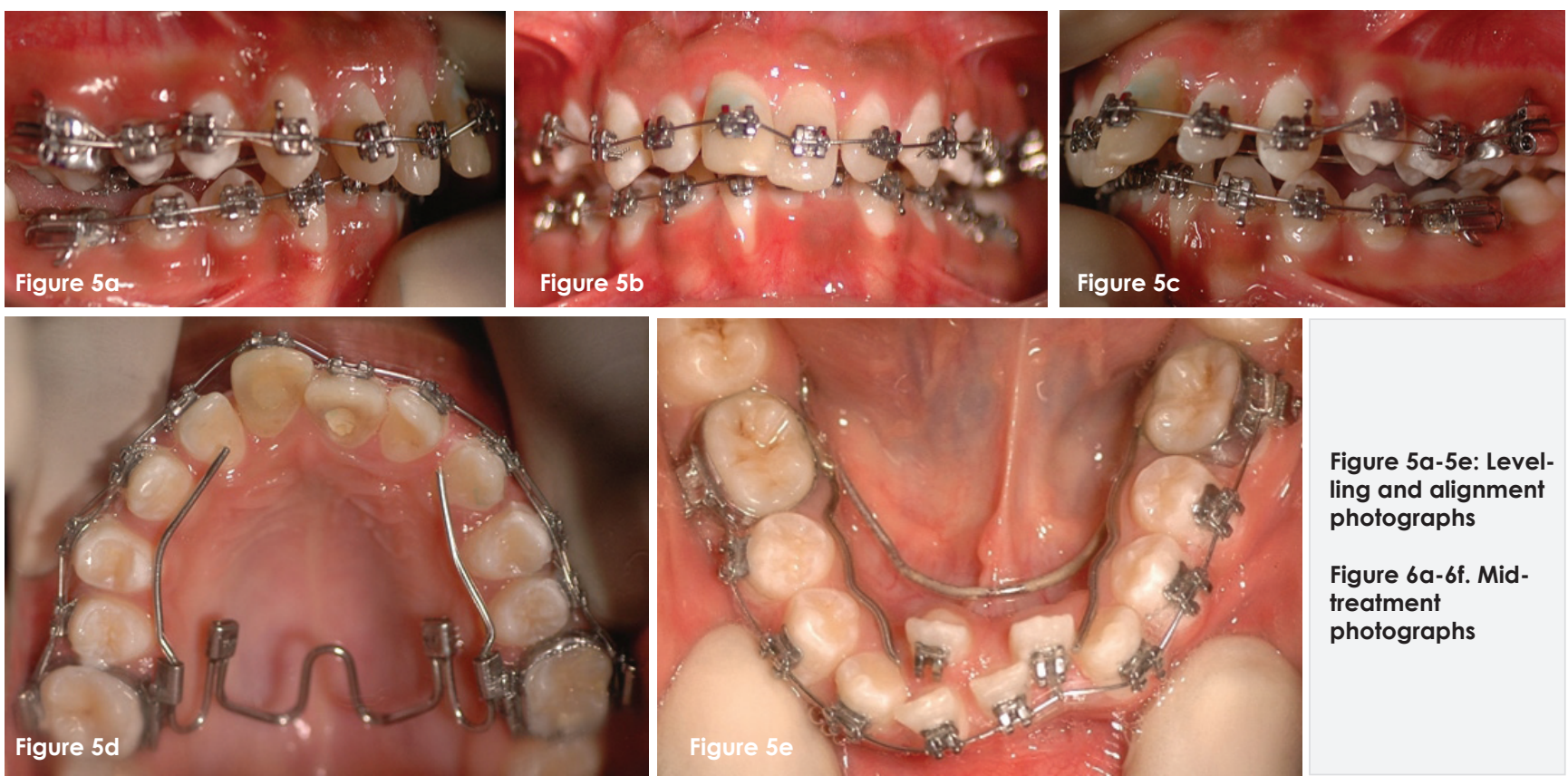

Figure 5a-5e: Levelling and alignment photographs

Figure 6a-6f. Mid-

treatment

photographs
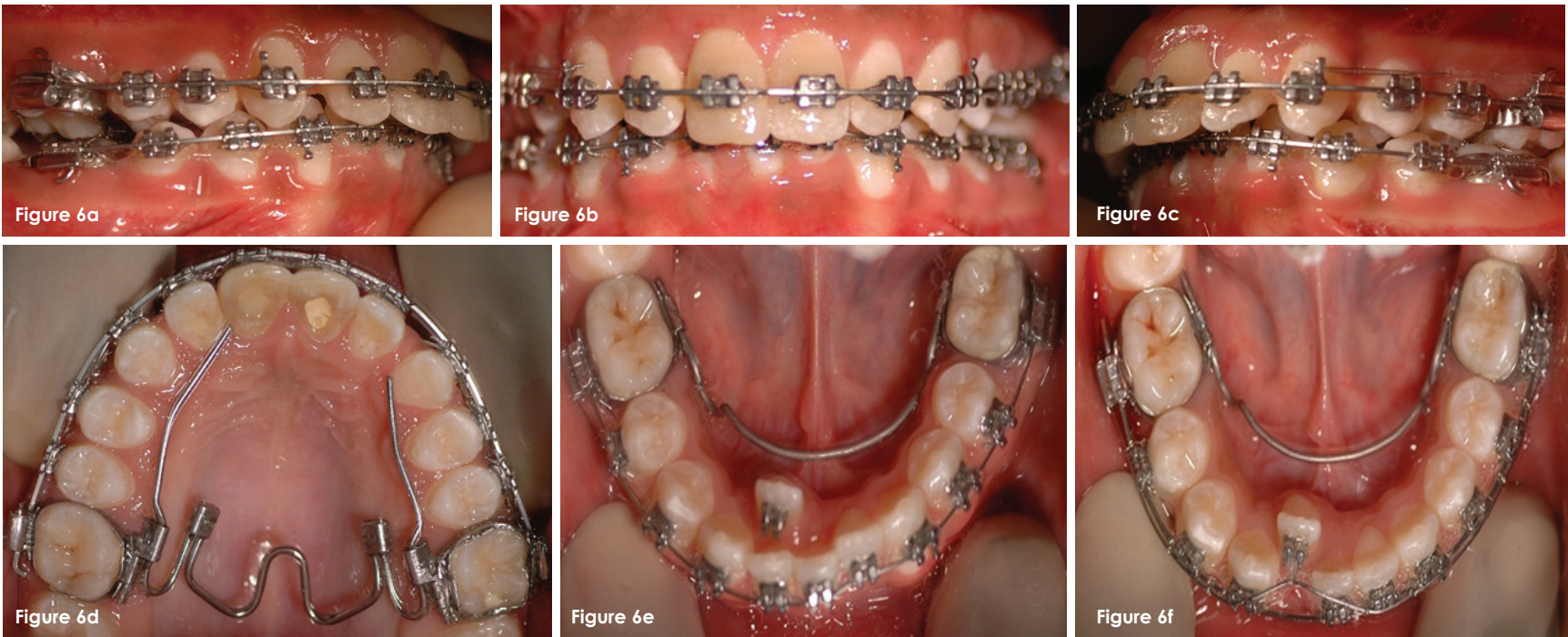

arches were banded and bonded. Bonding was done using 3M Unitek Gemini series 022 slot brackets. The initial arch wire 0.016 " NiTi was placed on both upper and lower arches (Figure 5a-5e). The in-standing lower left lateral incisor was not bonded initially.

After the initial wire, $0.016 \times 0.022$ " NiTi wire followed by $019 \times 25$ " NiTi were placed for the sequential leveling (Fig. $6 a-6 e)$. Stainless steel wire of $019 \times 025 "$ in upper and lower arch was used for final leveling. During the leveling phase, canines moved distal with the lace back force and the space available in the anterior region was utilized for the intrusion of the upper incisors. The upper arch was segmented into anterior and posterior segments and $019 \times 025$ " sectional stainless steel wires were placed in both the segments. Connecticut Intrusion Arch (CIA) wire was tied to the anterior segment for the intrusion of the upper incisor (Fig. 7a-7c). NiTl palatal expander was retained until the heavy stainless steel wire was used. Then the canine intrusion was done using utility arch (Fig. 8).

In the lower anterior region the space obtained by the expansion was not sufficient to bring about the alignment of lower incisors so it was decided to extract lower right central incisor as it was periodontally compromised too. .014" auxiliary NiTi wire was placed and the left lateral incisor was aligned (Fig. 6f). 

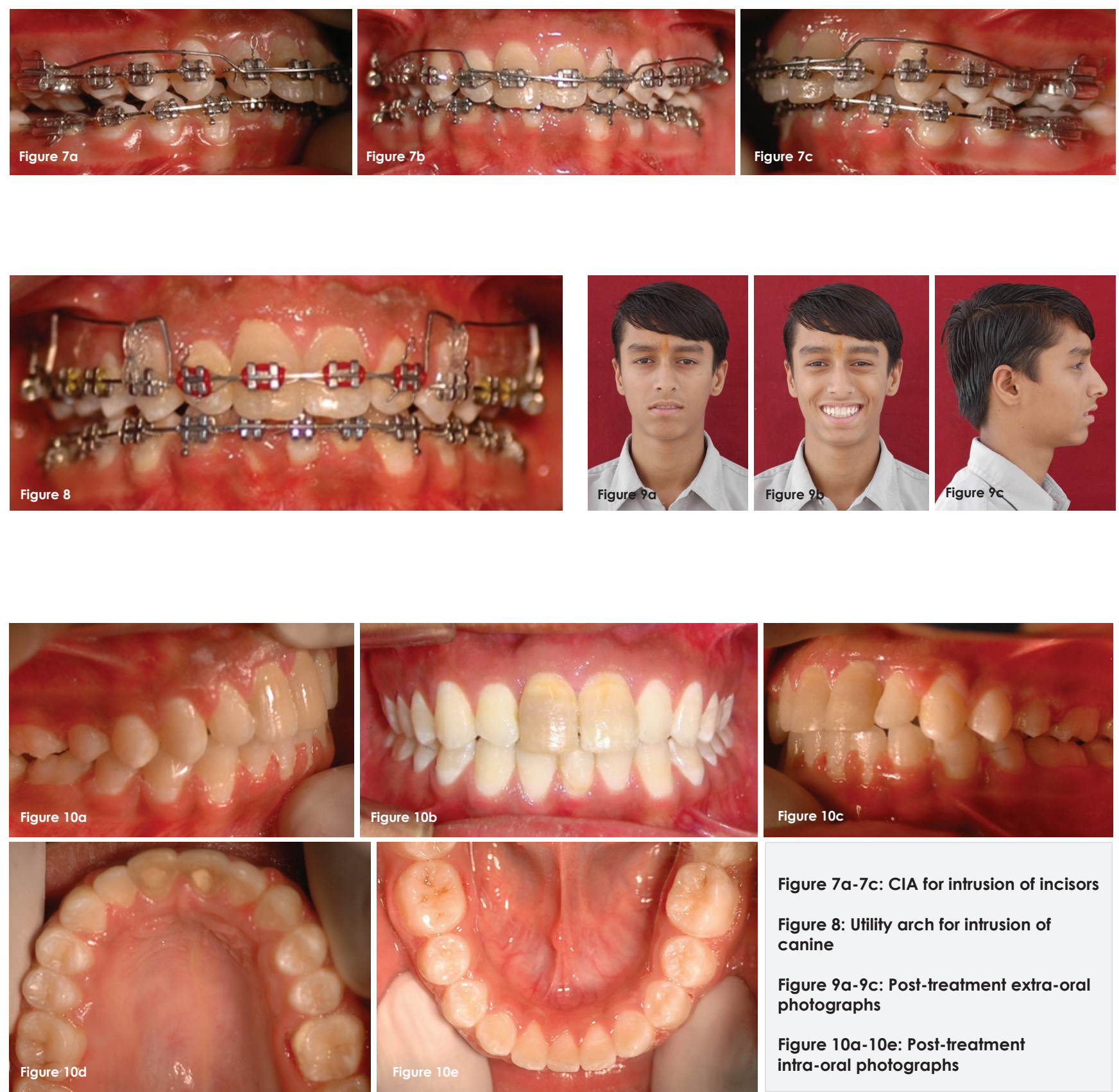

Figure 7a-7c: $\mathrm{CIA}$ for intrusion of incisors

Figure 8: Utility arch for intrusion of canine

Figure 9a-9c: Post-treatment extra-oral photographs

Figure 10a-10e: Post-treatment intra-oral photographs

\section{Treatment result and retention}

It took two years duration to complete the treatment. Posttreatment photographs revealed well expanded arches with pleasing profile (Fig. 9a-9c, 10a-10e). Upper and lower bonded retainers were used for retention. Post-treatment photographs after five years showed well retained occlusion with good intercuspation (Fig 1 1a-1 1c, 12a-12e). Though the posterior settlement looked incomplete in the immediate post-treatment photographs; later they settled well with good intercuspation.
Both immediate post-treatment and five-year-after treatment radiographs show well balanced occlusion (Fig 13a-13b and Fig15a-15b). The overall and regional superimposition of maxilla and mandible (Fig 14a-14c) showed forward movement of maxillary and mandibular base along with the dentition. Both upper and lower molars were supra-erupted and slight upper incisor intrusion were seen. The comparison of the pre- and post-treatment lateral cephalograms suggest lower incisor proclination and overall growth of the face in class III skeletal pattern (Table 1). 

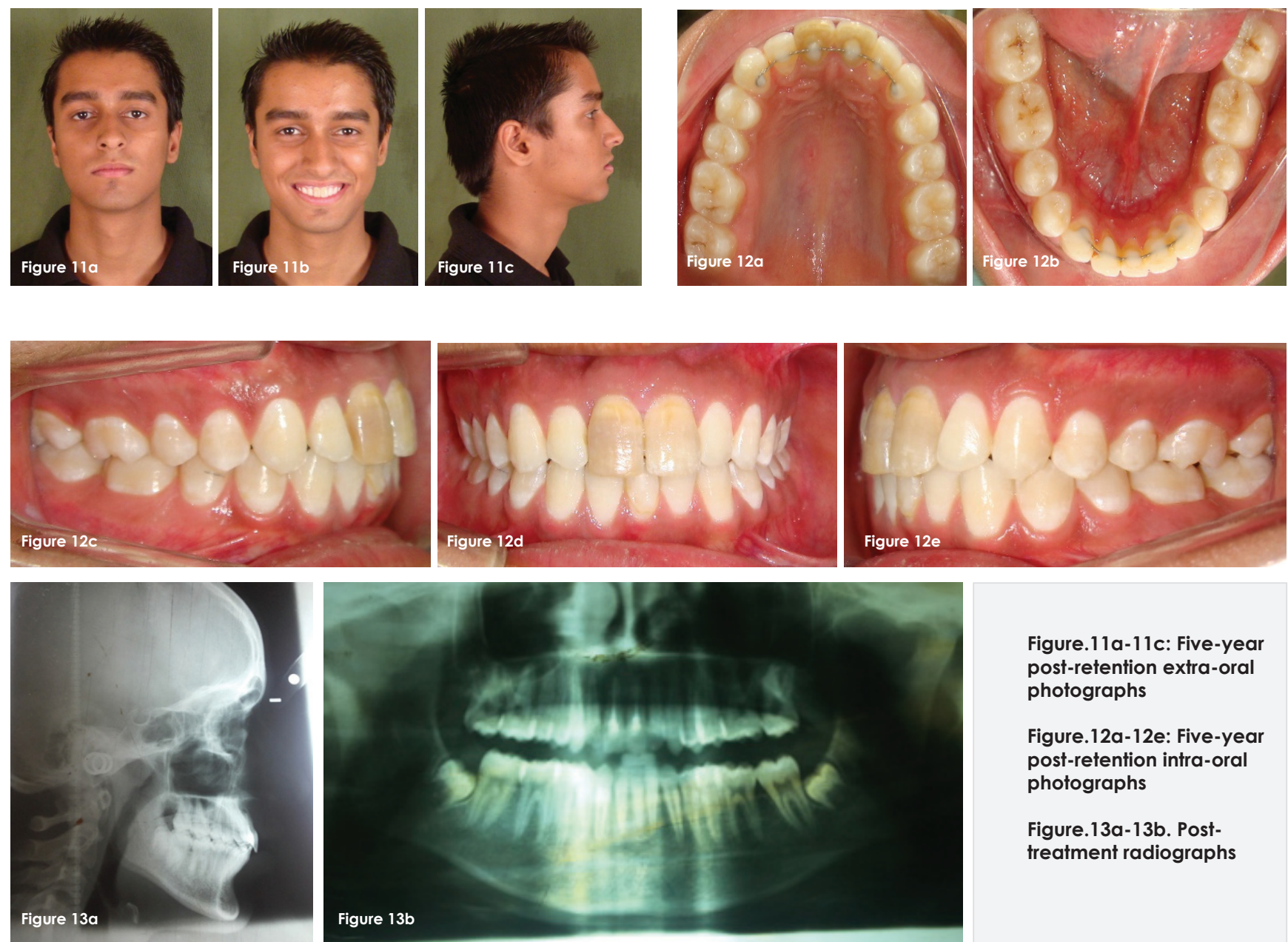

Figure.11a-11c: Five-year post-retention extra-oral photographs

Figure.12a-12e: Five-year post-retention intra-oral photographs

Figure.13a-13b. Posttreatment radiographs
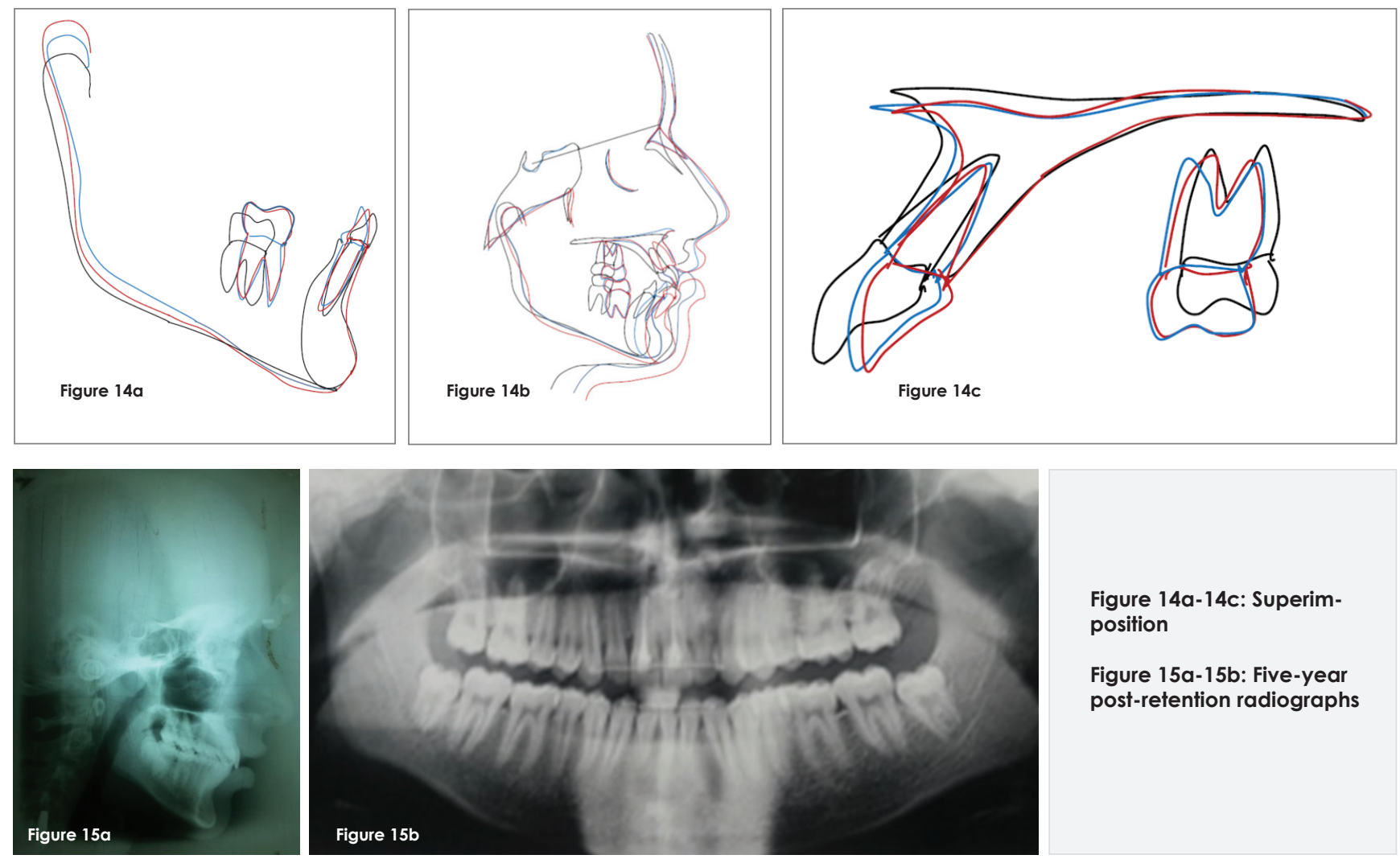

Figure 14a-14c: Superimposition

Figure 15a-15b: Five-year post-retention radiographs 

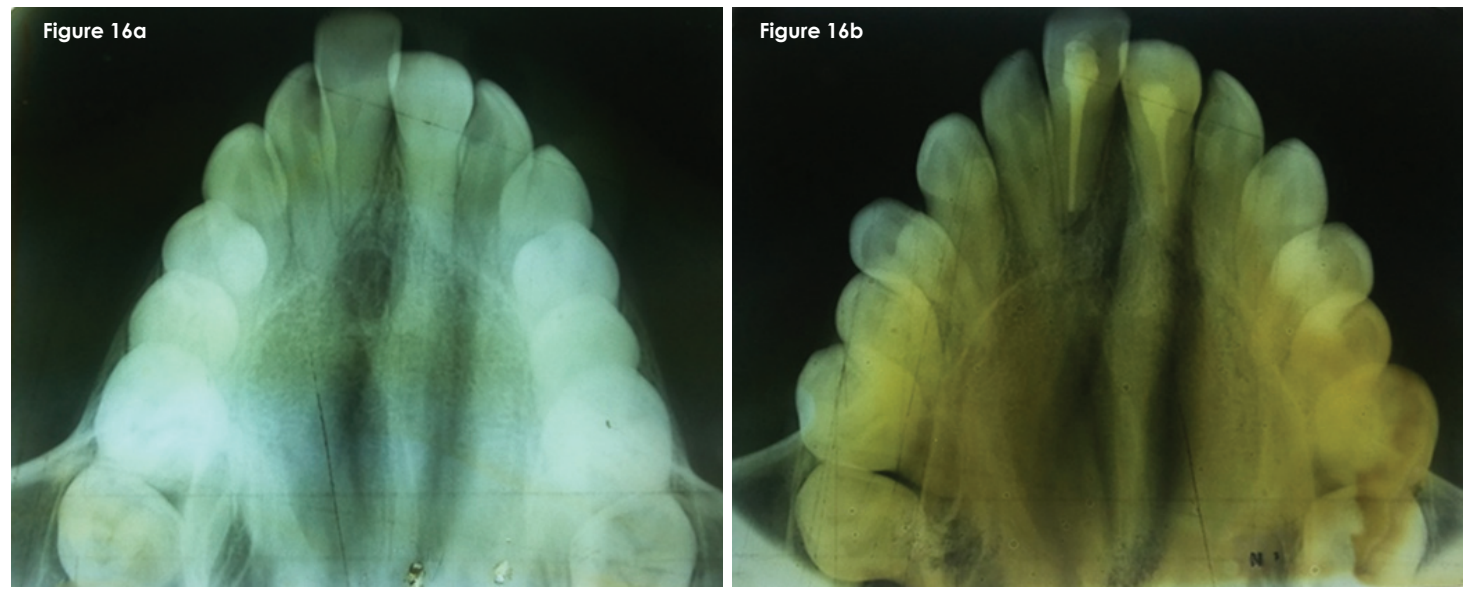

Figure 16a-16b: Comparison of pre-treatment and post-expan sion maxillary occlusal view

Table 1: Comparison of cephalometric changes

\begin{tabular}{|l|c|c|c|}
\hline \multicolumn{1}{|c|}{ Parameters } & Pre-treatment & Immediate post-treatment & $\mathbf{5}$ years after treatment \\
\hline SNA & $76^{\circ}$ & $75^{\circ}$ & $74^{\circ}$ \\
\hline SNB & $74^{\circ}$ & $73^{\circ}$ & $73^{\circ}$ \\
\hline ANB & $2^{\circ}$ & $2^{\circ}$ & $1^{\circ}$ \\
\hline SN-MP & $33^{\circ}$ & $35^{\circ}$ & $32^{\circ}$ \\
\hline FMA & $25^{\circ}$ & $28^{\circ}$ & $23^{\circ}$ \\
\hline UI-SN & $116^{\circ}$ & $104^{\circ}$ & $101^{\circ}$ \\
\hline LI-MAN.PLANE & $95^{\circ}$ & $95^{\circ}$ & $98^{\circ}$ \\
\hline U1-NA (Angle) & $38^{\circ}$ & $31^{\circ}$ & $28^{\circ}$ \\
\hline U1-NA (Linear) & $9 \mathrm{~mm}$ & $7 \mathrm{~mm}$ & $6 \mathrm{~mm}$ \\
\hline LI-NB (Angle) & $24^{\circ}$ & $25^{\circ}$ & $29^{\circ}$ \\
\hline LI-NB (Linear) & $4 \mathrm{~mm}$ & $6 \mathrm{~mm}$ & $6 \mathrm{~mm}$ \\
\hline
\end{tabular}

\section{DISCUSSION}

With the advent of newer techniques, orthodontic treatment has become simpler, efficient and comfortable. The NiTi palatal expander is one such innovation which has made the expansion procedure comfortable as well as efficient. ${ }^{1,4}$ The temperature activated arms produce light continuous force on mid-palatal suture. The amount of expansion achieved in the present case was $10 \mathrm{~mm}$ (Fig. 16a-16b).

Although lower incisor extraction for the orthodontic purpose is rarity, certain cases can sustain the loss of a lower incisor and still can produce a good occlusion and pleasing facial esthetics. ${ }^{2,3,5,6}$ The present case is a good example of such treatment modality. The extracted lower incisor was periodontally compromised since the beginning, the etiology of which was probably the deep bite with constant occlusal trauma and poor oral hygiene. The present case which otherwise would have gone for the traditional all premolar extraction has been treated using the conservative approach by the combination of arch expansion and a lower incisor extraction.

\section{REFERENCES}

1. Arndt WV. Nickel titanium palatal expander. J Clin Orthod 1993; 27:129-37.

2. Raju DS, Veereshi AS, Naidu DL, Raju BH, Goel M, Maheshwari A. Therapeutic extraction of lower incisor for orthodontic treatment. J Contemp Dent Pract 2012; 13(4):574-7.

3. Kokich VG, Shapiro PA. Lower incisor extraction in orthodontic treatment. Angle Orthod 1984; 54:139-53.

4. Abdoney MO. Use of the Arndt nickel titanium palatal expander in cleft palate cases. J Clin Orthod 1995; 29:496-9.

5. Riedel RA, Little RM, Bui TD. Mandibular incisor extraction. Post-retention evaluation of stability and relapse. Angle Orthod $1992 ; 62: 103-16$.

6. Bahreman AA. Lower incisor extraction in orthodontic treatment. Am J Orthod 1977; 72:560-7. 